\title{
Application of tephra volume models to ejecta volumes from subsurface explosion experiments
}

\author{
A. H. Graettinger
}

\begin{abstract}
Deposit volume is a critical factor for reconstructing an explosive eruption. Volume estimate models typically used for large Plinian deposits have been adapted and improved repeatedly over the last few decades. Less work has been done to refine a method for estimating the volume from smaller deposits produced by discrete phreatic and phreatomagmatic explosions. The characterization of the volume and distribution of deposits is required to quantify the physical hazards presented by different explosion types and develop appropriate models of future eruptions. Six classic tephra volume models were assessed using a dataset from subsurface explosion experiments. The models typically did a poor job modelling the volume of proximal deposits as a component of total deposit volume of discrete explosion deposits. Models reproduced medial and distal deposit volumes with greater success, particularly the Exponential model and a more recent Linear Regression model. It is therefore recommended, when possible, to use digital elevation models produced from GPS or laser-based methods to characterize proximal deposits separately and to use tephra volume estimates for medial and distal deposits. Additionally, this dataset enabled the comparison of ejecta volumes with crater diameters and highlighted that this relationship only holds for simple crater scenarios without any lateral vent migration, collapse or erosion of the crater under study. The assessment and improvement of these methods are required to ensure accurate deposit volumes as they serve as one of the most important inputs to hazard assessments and numerical models.
\end{abstract}

Keywords: Ejecta volume, Discrete explosion, Phreatomagmatic, Experimental volcanology, Quantification, Model evaluation

\section{Background}

Explosive eruption deposit volumes are one of the most important factors in the characterization of eruption size, and also inform reconstructions of eruptive behavior. Most approaches to characterizing tephra volumes have focused on deposits produced by sustained eruption columns (violent Strombolian, sub-Plinian, Plinian; Pyle 1995; Fierstein and Nathenson 1992; Bonadonna and Houghton 2005; Bonadonna and Costa 2012; Burden et al. 2013). Less work has assessed the distribution and volume of deposits from discrete explosions, particularly those through pre-existing debris-filled vents such as phreatic, hydrothermal, or phreatomagmatic explosions (Ruapehu 2007, Kilgour et al. 2010; Taal, Moore

Correspondence: agraettinger@gmail.com

University at Buffalo, Center for Geohazard Studies, 126 Cooke Hall, Buffalo, NY 14226, USA et al. 1966; Rotomahana, White and Ross 2011). These explosions can occur individually or as one of tens to hundreds of explosions in a sequence, producing a range of deposit volumes. Small volume deposits from discrete explosions are important to understand as they record events that may have little to no precursory activity and have been previously overlooked in the geologic record (Christenson et al. 2007; Kilgour et al. 2010). Here, measurements from a growing dataset of meter-scale crater experiments were used to test the applicability of six common volume estimation models to estimate discrete explosion-generated deposit volumes. Experiments involving buried chemical explosives have been used successfully as an analog for discrete explosions in debris-filled vents producing transport and depositional processes that have been observed in natural eruptions (Breard et al. 2014; Graettinger et al. 2015a), with deposit \\ Springer Open}

(c) 2016 Graettinger. Open Access This article is distributed under the terms of the Creative Commons Attribution 4.0 International License (http://creativecommons.org/licenses/by/4.0/), which permits unrestricted use, distribution, and reproduction in any medium, provided you give appropriate credit to the original author(s) and the source, provide a link to the Creative Commons license, and indicate if changes were made. 
characteristics similar to those of tephra ring deposits (Graettinger et al. 2015a, Graettinger et al. 2015b; Valentine et al. 2015b).

Standard methods of estimating tephra volume are based on assumptions about the decay of deposit thickness with distance away from a source and knowledge of the isopach areas produced by the deposit (Table 1). These methods include Exponential, Power Law, and Weibull modeled spatial distributions (Pyle 1995; Bonadonna and Houghton 2005; Bonadonna and Costa 2012). Variations on these methods that include a linear regression model dependent on deposit thickness measurements (Burden et al. 2013) have been introduced to move away from the interpretation required in the production of isopach maps inherent to the previous methods. Studies focused on crater morphology, such as military blast experiments, have been used to propose empirical relationships between crater size and ejecta volume (Lee and Mazzola 1989). Attempts to correlate crater volume with deposit volume were made by Sato and Taniguchi (1997), who estimated deposit volume using the crystal concentration method, which is based on anticipated crystal abundances relative to a starting magma. The crystal concentration method is clearly inappropriate for deposits that contain large quantities of lithic material, such as deposits produced by phreatomagmatic and phreatic explosions as studied here. However, we consider their relationship between crater and volume when discussing the experimental datasets presented here. These well-established methods have been studied in detail to constrain uncertainty of the input data and within the models themselves (Engwell et al. 2013; Klawonn et al. 2014a,b). This study aims to investigate the appropriateness of these approaches for small volume discrete explosion deposits. As discrete explosions can occur at nearly any volcano, and frequently with minimal to no warning (e.g. Kilgour et al. 2010; Breard et al. 2014), they represent a significant, but poorly constrained hazard for people living on or visiting volcanoes.

The above methods have been applied to a range of deposit types, including those produced by phreatomagmatic and phreatic (hydrothermal) explosions. For example the volume of historic eruption deposits of the Rotomahana eruption in New Zealand $\left(0.3 \mathrm{~km}^{3}\right)$ was estimated using the Exponential model (Pyle 1995; White and Ross 2011). Recently these types of deposits have been divided into discrete elements, i.e. jetted ash $\left(1 \times 10^{5} \mathrm{~m}^{3}\right)$ versus ballistics $\left(1.6 \times 10^{5} \mathrm{~m}^{3}\right)$ by Kilgour et al. (2010). Alternatively, some investigators have focused only on the constructional cone while neglecting distal deposits (Guilbaud et al. 2012; Valentine and Cortés 2013). There are also published deposit volume estimates where the study does not explicitly describe the methods used to estimate deposit volume, such as Taal $\left(0.09 \mathrm{~km}^{3}\right.$ tephra $)$ by Moore et al. (1966), or that are based on comparisons to other historic eruptions without independent modeling (Kereszturi et al. 2013). This diversity of approaches is based, in part, on the unique geometry and small volumes of these types of deposits. As the experimental deposits discussed herein are well constrained and preserve proximal, medial and distal ejecta deposits produced by discrete subsurface explosions through granular media, they provide a unique opportunity to validate the fit of these models to estimating small discrete explosion deposit volumes.

\section{Methods}

Subsurface explosion experiments were used to model discrete explosion processes similar to those of phreatic, phreatomagmatic explosions and other discrete explosions through debris-filled vents (Graettinger et al. 2014, 2015a,b; Valentine et al. 2015a). The experiments produce deposits

Table 1 Common models of tephra volume and inputs

\begin{tabular}{|c|c|c|c|c|}
\hline Model (abbreviation) & Inputs & & Constraints & Reference \\
\hline $\begin{array}{l}\text { Incremental and Expanded } \\
\text { Incremental (IncT) }\end{array}$ & $\begin{array}{l}\text { Thickness (or mass per } \\
\text { unit area and density) }\end{array}$ & Isopach area & $\begin{array}{l}\text { Layer-cake type method limited by data } \\
\text { available. }\end{array}$ & Rose et al. 2008 \\
\hline Exponential (Exp) & $\begin{array}{l}\text { Thickness (or mass per } \\
\text { unit area and density) }\end{array}$ & Isopach area & $\begin{array}{l}\text { Must determine the number of segments } \\
\text { to be computed. }\end{array}$ & $\begin{array}{l}\text { Pyle 1995, Fierstein and } \\
\text { Nathenson } 1992\end{array}$ \\
\hline Power Law (PL) & $\begin{array}{l}\text { Thickness (or mass per } \\
\text { unit area and density) }\end{array}$ & Isopach area & $\begin{array}{l}\text { Proximal and distal limits as inputs for } \\
\text { calculation. }\end{array}$ & $\begin{array}{l}\text { Bonadonna and Houghton } \\
2005\end{array}$ \\
\hline Weibull (W) & $\begin{array}{l}\text { Thickness or mass per } \\
\text { unit area }\end{array}$ & Isopach area & $\begin{array}{l}\text { Includes a variable thinning rate }(\lambda) \text { and } \\
\text { thickness scaler }(\Theta) \text {. }\end{array}$ & Bonadonna and Costa 2012 \\
\hline Linear Regression Model (LRM) & $\begin{array}{l}\text { Thickness (or mass per } \\
\text { unit area and density) }\end{array}$ & $\begin{array}{l}\text { Distance from } \\
\text { source }\end{array}$ & $\begin{array}{l}\text { Requires widely dispersed field data and } \\
\text { minor data prep. for input into code. }\end{array}$ & Burden et al. 2013 \\
\hline Crater volume dependent (Cv) & Crater volume & - & $\begin{array}{l}\text { Requires high resolution crater volume. } \\
\text { Limited to final crater (except in } \\
\text { experimental scenario). }\end{array}$ & Lee and Mazzola 1989 \\
\hline
\end{tabular}

For all models that use deposit thickness measurements can also use mass loading (mass per unit area) if a deposit bulk density is known. In the case of the experiments an average bulk density of $1650 \mathrm{~kg} / \mathrm{m} 3$ was used 
between $0.15-0.99 \mathrm{~m}^{3}$ in volume, but share jet and crater phenomenology with larger explosions (Gould and Tempo 1981; Goto et al. 2001; Taddeucci et al. 2013; Graettinger et al. 2014). Comparisons of depositional facies from experimental deposits with natural deposits justify the use of this experimental dataset for deposit volume evaluation (Graettinger et al. 2015a,b; Valentine et al. 2015b). Based on the ejecta volumes the 'eruptions' produced in these studies would be considered a VEI -6 by the extended VEI scale, proposed by Houghton et al. (2013) to include small eruptions. These experiments were conducted with setups where material type, depth of burial, explosion energy and number of explosions were varied. Military explosion experiments typically scale deposits distribution relative to crater radius (Lee and Mazzola 1989; Gould and Tempo 1981) relating deposits from craters with diameters from meter to kilometers. Explosions used for this study had ejecta distribution of greater than two times the crater radius (typically $>5 \mathrm{~m}$ ) from experiments conducted between May 2013 and June 2014 (Graettinger et al. 2014; Valentine et al. 2015a; Graettinger et al. 2015a). Seventeen blasts from the experimental dataset meet this criterion, where ejecta distributions were typically 12 to 20 times the crater radius. Of these, nine were primary explosions in undisturbed material with no topography, seven explosions occurred in previous craters, and one blast occurred through a retarc or inverted crater (Graettinger et al. 2014). Four of the final craters were the result of two or more explosions (multiblast systems). Deposits were composed of proximal deposits that produced a constructional cone that defined the crater rim, medial deposits consisting of a continuous blanket with slopes $<10^{\circ}$, and distal ejecta of isolated clasts that represented the greatest dispersal of ejecta (Graettinger et al. 2015a).

Proximal ejecta deposits were characterized by $1 \mathrm{~cm}$ horizontal resolution digital elevation models (DEM) with vertical resolutions of $1-2 \mathrm{~cm}$ produced from photogrammetry of before and after each explosion. Medial and distal ejecta deposits were measured in units of mass loading, or mass per unit area $\left(\mathrm{kg} / \mathrm{m}^{2}\right)$ at one meter increments in two arrays of sample boxes extending away from the explosion locus. The first measurement was between 1.5 and $2 \mathrm{~m}$ from the center of the blast so that the collection boxes did not disrupt the formation of the crater. With the exception of one explosion, all proximal deposits occurred within $2 \mathrm{~m}$ of the blast center and did not interact with the sample boxes. Deposits were collected as individual beds and were estimated both independently and cumulatively to estimate the total deposit volume. The experimental set up enabled the near-continuous collection of ejecta to the maximum distal extent of measurable ejecta $(15-20 \mathrm{~m})$. The two ejecta-sample arrays showed local heterogeneities from concentrated rays (Graettinger et al. 2015b) and were averaged to represent the dominant trend of deposit decay. Isopach area was calculated from the sample box position to the previous sample box position, creating circular isopachs. Visual inspection of the distribution of ejecta and the lack of wind (measured $<1 \mathrm{~m} / \mathrm{s}$ ) indicates that such symmetry is reasonable.

Experiment volume data are presented as three 'control' volumes that were used to compare with model volumes: $V m, V t$, and $V s . V m$ represents the medial and distal ejecta proportion of the deposit and is considered a minimum ejecta volume for a given explosion. As the models being evaluated do not produce independent proximal volume estimates $V p$ is not evaluated separately, the proximal component is instead evaluated as a contribution of $V t$. Photogrammetry was not collected for medial and distal ejecta as the deposit thickness $(\leq 1 \mathrm{~cm})$ is within the vertical resolution for this technique. Medial and distal ejecta were emplaced on a relatively flat surface and not deformed by crater growth or collapse. The experimental deposits mantle the ground surface with only minor fluctuations in distribution in the form of concentrated rays (Graettinger et al. 2015b). The decay of ejecta thickness away from a source was estimated using a graphical stepwise function based on thickness represented by the collected samples and isopach area (Rose et al. 2008). As the samples were measured as a mass per unit area $\left(\mathrm{kg} / \mathrm{m}^{2}\right)$ the bulk density of the deposit was required to determine the deposit thickness. The bulk density of the samples was measured in the laboratory after collection and an average value was applied to this conversion $\left(1650 \mathrm{~kg} / \mathrm{m}^{3}\right)$. The small spacing of measurements and regularity of the deposit means that this Incremental method is a reasonable minimum estimate of the medial and distal deposit volume $(\mathrm{Vm})$.

$V t$ is the total ejecta volume including the proximal ejecta that forms the crater rim. The proximal deposit was emplaced on the crater rim and the slope extending away from the rim. This proximal deposit frequently contributed up to $50 \%$ of the deposit volume (Graettinger et al. 2015a). The contribution of individual explosions in multi-blast experiments to this portion of the deposit was constrained by the change between consecutive DEMs. The proximal deposit and the $V m$ were combined to produce the total control volume $(V t)$ for the deposit. The comparison of a model's ability to predict both $V m$ and $V t$ serves as an estimate of the model's capacity to extrapolate the proximal deposits from $\mathrm{Vm}$ in the absence of available measurements.

For the final crater produced by multiple explosions a series deposit volume was calculated using a total mass loading for all explosions within the series and the final proximal volume measured from the DEM and called series volume $(V s)$. Additionally, the results of each method as applied to single (primary) explosion craters 
and subsequent blasts through a pre-existing crater (referred here as secondary) explosions were compared.

\section{Model evaluation}

The six volume models were evaluated for their ability to reproduce the three experimental 'control' volumes: 1) the medial and distal ejecta blanket $V m$ (constrained by sample boxes), 2) the total deposit volume ( $V m$ plus the proximal ejecta volume from the DEM) known as $V t$, and 3) the total series volume Vs. Volumes are represented by abbreviations that use a portion of the model name (e.g. Exp $=$ Exponential, $\mathrm{PL}=$ Power Law) and $V m$, $V t$, or $V s$ to represent the control volume it was compared against (Additional file 1: Table S1). The success of replicating these control volumes is represented by a ratio of the modeled volume to the control volume (e.g., $V t E x p / V t$ is the ratio that compares the Exponential model total volume estimate with the total control volume). Additionally, the consistency of the results is represented by a coefficient of variation, which is the ratio of the standard deviation to the mean value. Models that produce a ratio of modeled to control volume that are closer to one and that have lower variation are considered more successful.

The following commonly used tephra volume models were compared with the data: expanded Incremental, Exponential, Power Law, Weibull, Linear Regression Model (LRM), and Crater Dependent (Cv). Several of these models can be calculated using a simple spreadsheet, with the exception of LRM which was computed using a script in R (Burden et al. 2013; R Core Team 2012). For the three most common models (Exponential, Power Law and Weibull) a java based program called AshCalc (Daggitt et al. 2014) is freely available at vhub.org/resources/ashcalc. Model computed $V m, V t$ and $V s$ results are listed in Table 2.

\section{Expanded incremental method (IncT)}

The Incremental method for calculating $V m$ described above may be extended to estimate the total deposit volume, including the proximal ejecta ring, by including thickness observations from the ring. The proximal ring was measured as a thickness from the original deposit surface between explosions using a measuring stick and a DEM. The isopach area between the maximum proximal ring height and the first sample box was then calculated as the isopach area for the proximal deposits. Although the geometry of the proximal ring was not the same as a simple thinning sheet as estimated in the medial ejecta, no additional assumptions were applied to maintain a consistent input for all the models discussed here (Table 1). The proximal isopach and thickness was then combined with $V m$ to produce an estimated total volume. This expanded Incremental model (IncT) results in slightly higher volume estimate (1.11) but a very high variation
Table 2 Evaluation of models against Vm and Vt. Models are evaluated using a ratio of model volume/control volume for complete samples, primary blasts, secondary blasts and final craters. Variation is the coefficient of variation, which is the ratio of the standard deviation to the mean value. Models that produce a ratio of modeled to control volume that are closer to one and that have lower variation are considered more successful. Proximal volumes are only calculated by models as a component of $\mathrm{Vt}$ and are therefore not presented separately

\begin{tabular}{lllllll}
\hline & InCT & Exp & PL & W & LRM & CV \\
\hline All deposits (17) & & & & & & \\
Vm & - & 1.01 & 1.84 & 0.41 & 1.27 & - \\
Range & - & 1.68 & 10.76 & 1.23 & 2.13 & - \\
Variation & - & 0.70 & 1.34 & 0.60 & 0.63 & - \\
$V t$ & 1.11 & 0.85 & 0.38 & 0.40 & 0.53 & 1.62 \\
Range & 7.40 & 2.45 & 1.00 & 1.31 & 0.53 & 0.55 \\
Variation & 1.48 & 0.80 & 1.03 & 0.74 & 0.49 & 0.58 \\
Primary (9) & & & & & & \\
$\quad$ Vt & 0.97 & 0.71 & 0.46 & 0.43 & 0.65 & 1.21 \\
Range & 1.86 & 0.86 & 0.94 & 0.37 & 0.67 & 2.20 \\
Variation & 0.66 & 0.21 & 0.66 & 0.31 & 0.35 & 0.62 \\
Secondary (8) & & & & & & \\
$\quad$ Vt & 1.60 & 1.15 & 0.36 & 0.42 & 0.35 & 2.22 \\
Range & 7.78 & 2.45 & 1.47 & 1.37 & 0.93 & 2.23 \\
Variation & 1.74 & 0.92 & 0.82 & 1.12 & 0.77 & 0.46 \\
Series (4) & & & & & & \\
$\quad$ Vs & 0.45 & 0.52 & 0.32 & 0.30 & 0.49 & 1.52 \\
Range & 0.32 & 0.42 & 0.76 & 0.42 & 0.69 & 0.95 \\
Variation & 0.40 & 0.36 & 1.06 & 0.57 & 0.25 & 0.46 \\
\hline
\end{tabular}

and range (Table 2; Fig. 1). The variability was greatest for explosions produced through a crater, most of the outlier estimates were from this group. Primary explosion deposits had the best fit (0.97) for this model with a moderate variation. The $V s$ estimates were consistently low (0.45).

\section{Discussion}

As this expanded Incremental model is predominantly based on the same data as was used in the estimation of $V m$, the source of variability is easily attributed to the difficulty in characterizing the proximal deposits with one measurement. This difficulty is most apparent for blasts through an existing crater when the change in proximal deposits can be subtle but nevertheless has a significant effect on deposit volumes.

\section{Exponential model (Exp)}

The Exponential model outlined by Fierstein and Nathenson (1992) and Pyle (1995) is based on the 

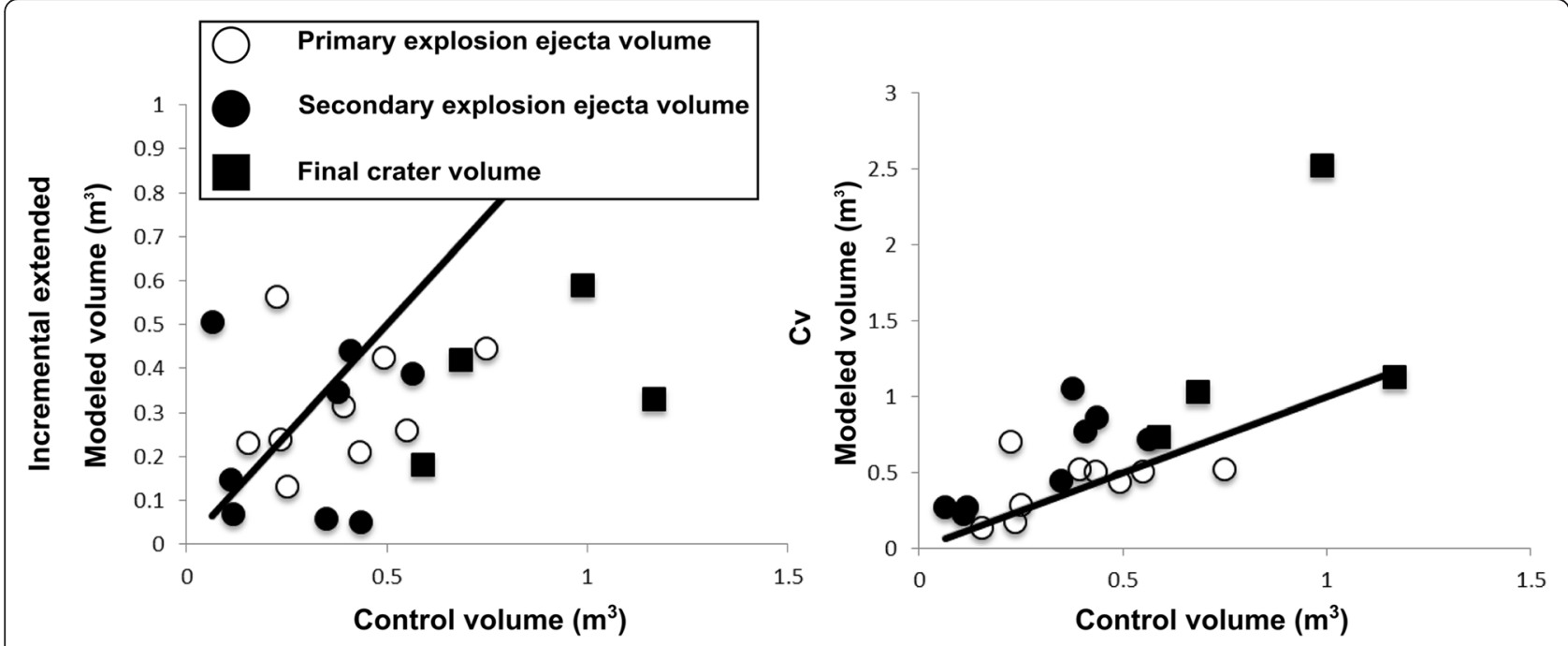

Fig. 1 Expanded Incremental total volume (IncT) model and Volume dependent (Cv) model with the control volume. The line represents an ideal fit distribution

exponential relationship between thickness and the square root of the isopach area:

$$
\mathrm{T}(\mathrm{x})=\mathrm{c} \mathrm{e}^{-\mathrm{mx}}
$$

where $\mathrm{T}$ is thickness at a distance $\mathrm{x}$ (from crater center), $\mathrm{c}$ represents the maximum thickness (near vent) and $\mathrm{m}$ is the rate of decrease in tephra thickness. This model allows for a variable rate of thinning, which can be estimated by fitting multiple exponential fits (segments) to the data. For the experimental data, a thickness was calculated from mass loading measurements by assuming a bulk density of the ejecta of $1650 \mathrm{~kg} / \mathrm{m}^{3}$, the average bulk density calculated from the materials used.

The estimation of $\mathrm{Vm}$ using the Exponential model used only one line segment and produced relatively consistent estimates that were on average 1.01, successfully replicating the $V m$ (Table 2). The selection of segments for the Exponential model is typically based on the shape of the curve on a plot of square root of isopach area versus deposit thickness. For Plinian deposits it is assumed that two segments are required for zones of distinct settling velocities (Bonadonna et al. 1998), which is not likely a significant process in discrete explosion jets (Graettinger et al. 2015a). In this case, the use of one or two segments was determined on the quality of fit to $V t$ where volume estimate closer to the control volume was used. The VtExp values averaged 0.85 but increased variability relative to $V m$ (Table 2, Fig. 2). The primary explosion and $V s$ estimates had low variation, but the secondary explosions had a variation of up to 0.92 .

\section{Discussion}

While the Exponential model successfully reproduced $V m$ for the experimental dataset, the estimates of total volume were more variable, and underestimated the control volume. This variability is likely to be a result of poor estimations of the proximal contribution to the volume. Secondary explosions produced volume estimates either one third or two times $V t$ (See Additional file 1). This is likely due to the dynamic nature and increasing contribution of the proximal ring, where deposition can result in negative changes in elevation (thickness) but a volume increase through deposition on the slopes of the proximal ring. As the volume contribution in the proximal ring increases with subsequent explosions (Graettinger et al. 2015a), this proximal zone will be difficult to characterize with only a thickness measurement and assumptions of thickness decay with distance. This underestimation is not just limited to small volume estimates for individual beds, but influences the series volume $(V S)$ as the proximal volume contribution increases overall as explosion numbers increase (Graettinger et al. 2015a). This model is best suited for estimations of medial and distal components of ejecta volumes.

Power Law model (PL)

Similar to the Exponential model, the Power Law technique calculates the volume from a scaled relationship of the square root of isopach area decreasing by a power law relationship:

$$
\mathrm{T}(\mathrm{x})=\mathrm{cx}^{-\mathrm{m}}
$$

where $\mathrm{T}$ is thickness at a distance $\mathrm{x}, \mathrm{c}$ is a scaling factor, $\mathrm{m}$ characterizes the rate of decrease of tephra thickness 


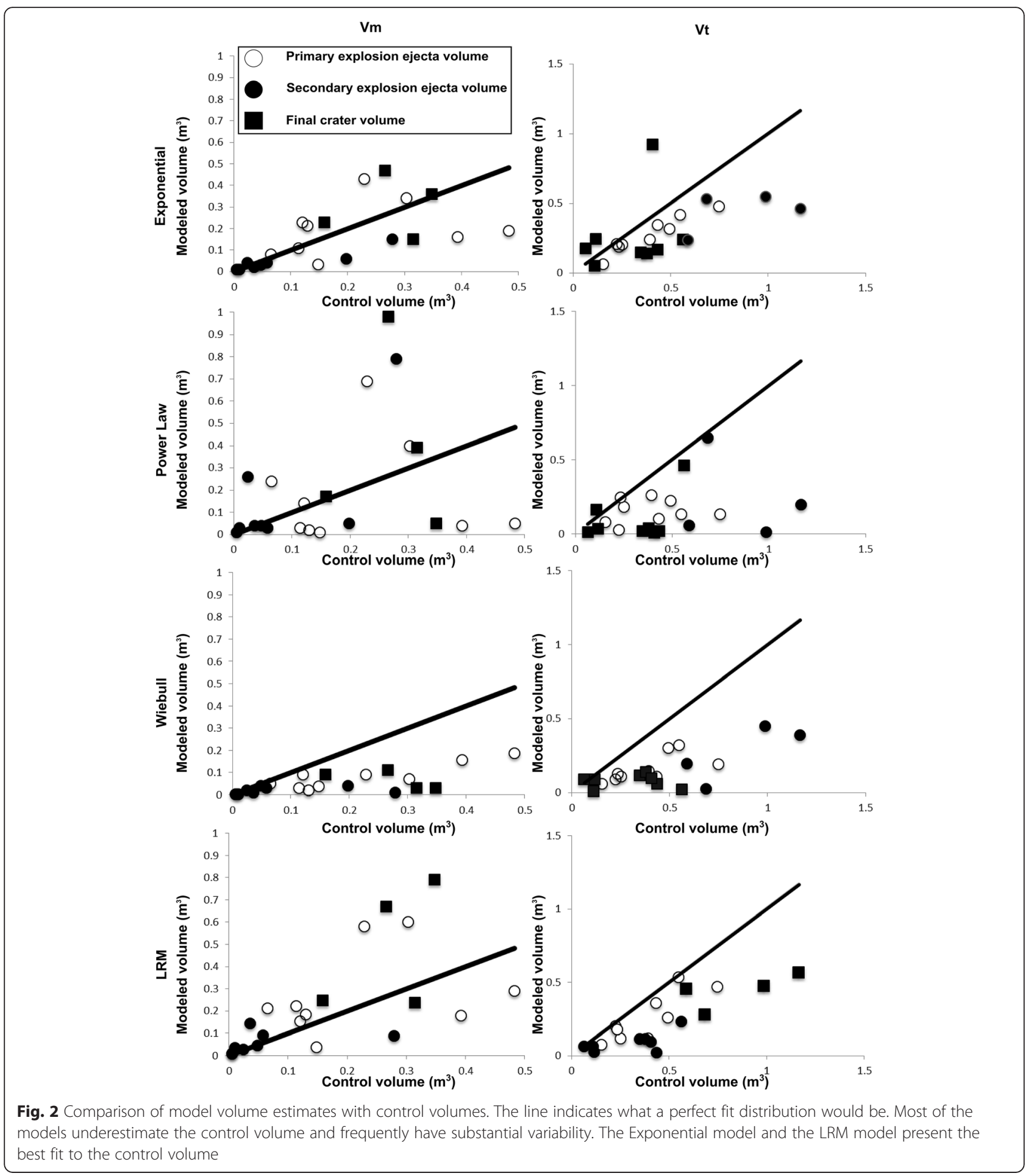

(Bonadonna and Houghton 2005). This requires the establishment of distal limits for the integral that represent the proximal and distal limit of the deposit (Table 1). The model is sensitive to these limits and is therefore dependent on the quality of field observations. The proximal limit used for these experiments was based on the position of the crater rim, even for $V m$ estimates. The Power Law model produces an overestimate of $V m$ (1.86) but an underestimate of $V t(0.39)$ (Table 2). The fit for primary explosions was typically better than for multiple-blast explosions and the results for $V s$ were variable. 


\section{Discussion}

The addition of a single data point and the selection of the proximal limit significantly affected the volume calculated by this model. The estimate of VmPL is an overestimate; however $V m P L$ is still significantly below $V t$ even when adjusting the limits to incorporate the proximal region. P1 and P2 from 2013b each have single explosions that produce exceptionally high values for $V m P L$ that suggests a sensitivity of the model to deposit thickness decay that is less rapid within the first few meters of the crater, in contrast with the Power Law curve. While the volume estimates for VtPL underestimate the control volume, they show improved consistency relative to $V m P L$ and the extreme results from P1 and P2 2013b were not observed due to the improved fit from a larger dataset. Consequently, the addition of multiple measurements in the critical proximal zone may result in more robust results (Fig. 2). However, in cases of limited proximal data this model is better suited to broad dispersed deposits than proximal-rich deposits.

\section{Weibull (W)}

The Weibull model was developed to combine the best features of the Exponential and Power Law models, and is based on the assumption that thickness scales with the square root of the isopach area with a Weibull distribution to describe the decay (Bonadonna and Costa 2012). This relationship can be expressed:

$$
\mathrm{T}(\mathrm{x})=\theta(\mathrm{x} / \lambda)^{\mathrm{n}-2} * \exp \left[-(\mathrm{x} / \lambda)^{\mathrm{n}}\right]
$$

Where $\mathrm{T}$ is thickness at a distance $\mathrm{x}, \mathrm{\theta}$ is a constant thickness scale, $\lambda$ is the rate of decay, and $n$ is a dimensionless shape parameter. The $\lambda$ parameter enables variation in the thinning rate. The determination of optimal $\lambda$ and are based in part on the knowledge of the deposit and are optimized, reducing the squared relative residuals to produce the best fit to the data (Bonadonna and Costa 2012; Daggitt et al. 2014). As with the Power Law, the volume calculation is dependent on these parameters and may be limited in conditions of small data sets. The Weibull model consistently underestimated both $V m$ and $V t$ by up to an order of magnitude particularly at larger volumes (Fig. 2; Table 2).

\section{Discussion}

The Weibull model is highly sensitive to its input values, which are selected through an understanding of the input data and iterative computation of constants. The Bonadonna and Costa (2012) spreadsheet uses a built-in solver in Excel to help reduce the residuals when selecting $\lambda$ and $\Theta$. The AshCalc program enables the input of multiple parameters with a controlled number of iterations to derive the most appropriate values of $\Theta$ and $\lambda$
(Daggitt et al. 2014). Estimates using optimized input parameters produced volume estimates for experimental data consistently below the control volumes. This underestimation was greatest for subsequent explosions, indicating that the sensitivity to proximal deposits is high, as with the previous models (Fig. 2). This model behaved consistently across all estimates but could not produce appropriate magnitudes for volume estimates for any of the experimental deposits.

\section{Linear Regression Model (LRM)}

Burden et al. (2013) proposed a log linear regression model based on deposit thickness measurements without the interpretation associated with isopach maps. This model assumes a log linear relationship between deposit thickness and distance where the error is calculated using Bayesian statistics (Table 1):

$$
\mathrm{T}(\mathrm{x})=\beta \mathrm{d}+\alpha
$$

The natural $\log$ transformation of the thickness data (thickness $T$ at distance $x$ ) is modeled where $\beta$ is a decay term for thickness with distance, $d$ is distance and $\alpha$ is the term to describe the error. A script of $\mathrm{R}$ code was provided by Burden et al. (2013) to enable processing of thickness point data from the field. The program requires a minimum scale of deposit thickness and volume and the experiments were artificially scaled to operate the code. As the experimental thickness measurements were in two transects (not distributed around the deposit constrained by natural exposures) four arrays of averaged thickness data were input into the model to represent its symmetrical distribution. The LRM model reasonably reproduced $V m$ (Fig. 2) but typically underestimated Vt (Table 2). Variation for primary and Vs estimates were low, but nearly double for secondary explosions (Table 2).

\section{Discussion}

The LRM model produced reasonably consistent volume estimates relative to the other models presented here (Fig. 2). The success of $V m$ estimates, but underestimation of $V t$, suggests a weakness in constraining the steep proximal deposits observed here. The experimental deposits with the largest $V m$ s, produced by primary blast deposits (2013aP1 and 2013bP1), which resulted in LRMVm estimates that were quite large, and were closer to the deposit total volume, rather than $V m$. However, the overall consistency of results produced by this model suggests that the input of additional data points, particularly in the complex proximal deposit would result in reasonable deposit volumes. 


\section{Crater dimensions-dependent model (Cv)}

An empirical relationship between crater size and ejecta volume was derived from military blast testing of single explosion craters by Lee and Mazzola (1989), such that $V t C v=1.24 \cdot V c$, where $V c$ is crater volume. This relationship indicates that the volume of ejecta exceeds that of the surface crater for primary blasts. Crater volume here was calculated from the DEM from crater rim to bottom. As this relationship was derived from a system with no additional mass (i.e. no juvenile eruptive material), and similar to the setup used in the military blasts, this model was expected to hold up well for the experiments presented here. For craters produced by multiple explosions the change in volume was used to calculate $V t C v$. This method cannot independently estimate the volume of the medial and distal ejecta blanket.

The relationship between crater volume and ejecta volume was reproduced reasonably well for $V m$ and $V t$ where primary, multiple and $V s$ estimates behaved similarly (Table 2; Fig. 1). However, the model volumes diverge increasingly from the control volume as eruptive volume and explosion number increase. This model underestimated the volume of ejecta produced when the previous surface was a retarc (instead of cratered or flat), but the estimate was still within the range of other estimates.

\section{Discussion}

The excess volume of ejecta relative to crater volume is the result of the disruption of compacted, organized material by an explosion and the redistribution as ejecta and fallback. This indicates that the volume of the crater produced in previously undisturbed ground, or one that significantly excavates pre-existing topography, can provide a reasonable minimum threshold for the ejecta volume under controlled conditions. However, in multi-blast systems (secondary explosions) this Crater volume-based estimate is between 100 and $420 \%$ larger than $V t$. This model was successful for primary craters and those craters where the dimensions are predominantly controlled by a single explosion (i.e. a relatively larger or shallower scaled depth explosion).

This model lacks a rigorous connection to the complexity of multiple explosion eruptions that occur in natural systems and the variation in material properties resulting from different levels of fragmentation and deposition (decompaction, compaction, sorting etc.). Consequently, volume estimates based on the change in crater volume resulted in overestimates of ejecta produced. This only reinforces the caution expressed by Sonder et al. (2015) for using crater volume as a tool to reconstruct eruption energy as they can lead to an overestimate of the maximum explosion energy, in addition to ejecta volumes. Additionally, natural craters are typically not formed by explosions with a fixed vertical position, but are subject to lateral migrations of explosion locus. This results in complicated crater morphologies and more subsurface heterogeneities. Experiments that investigated the influence of vent migration conducted under similar conditions and those included in this study were unable to constrain the total volume of ejecta, although most of the volume was collected in the proximal zone (Valentine et al. 2015a). In addition to being limited to idealized scenarios without lateral vent migration, this method is limited to craters that have not experienced erosion or collapse to significantly alter the crater volume. The relationship between a simple crater (laterally fixed explosion locus with few explosions) and ejecta volume makes it worthwhile to investigate other relationships between ejecta volume and crater dimensions, with due consideration for additional variables as listed here.

\section{Discussion}

Sato and Taniguchi (1997) computed a log linear relationship between crater size and ejecta volume for magmatic and phreatomagmatic eruption deposits using their own volume estimates and some from the literature. Their observations suggested that phreatomagmatic craters were typically larger than those produced by magmatic explosions, and both are correlated with larger ejecta volumes than crater volume, similar to observations from experimental craters. A comparison of the model calculated volumes from this study with crater diameter was conducted to investigate apparent trends of crater diameter and ejecta volume when using different methods of estimating volume.

As expected, based on its approach, there was a strong log linear trend for crater diameter and volume estimates from the $C v$ model (Fig. 3a). There was also a moderate $\log$ linear trend for the control volume $V t$ and the Exponential model with crater diameter. There was no apparent correlation between ejecta volume calculated by the Weibull or LRM models with crater diameter (Fig. 3b). The Power Law volume estimates show an inverse linear relationship to that of the $C v$ model. In order to determine if the relationship observed from the experimental data is limited wholly by method, or if there was a reliable relationship between simple (no lateral migration) craters and ejecta volume, the control volume was divided into components: proximal and medial plus distal ejecta. A log linear trend between volume and crater diameter was not apparent for proximal and medial + distal volumes $(\mathrm{Vm})$, but was apparent for the combined volume $(V t)$ (Fig. 3b). This trend indicates that a reasonable relationship between the volume of material disrupted by an explosion is represented by both the crater volume and the ejecta volume in single explosion cases. However, as the number of explosions within a single crater increases, the correlation breaks down (Table 2, secondary explosions). The 

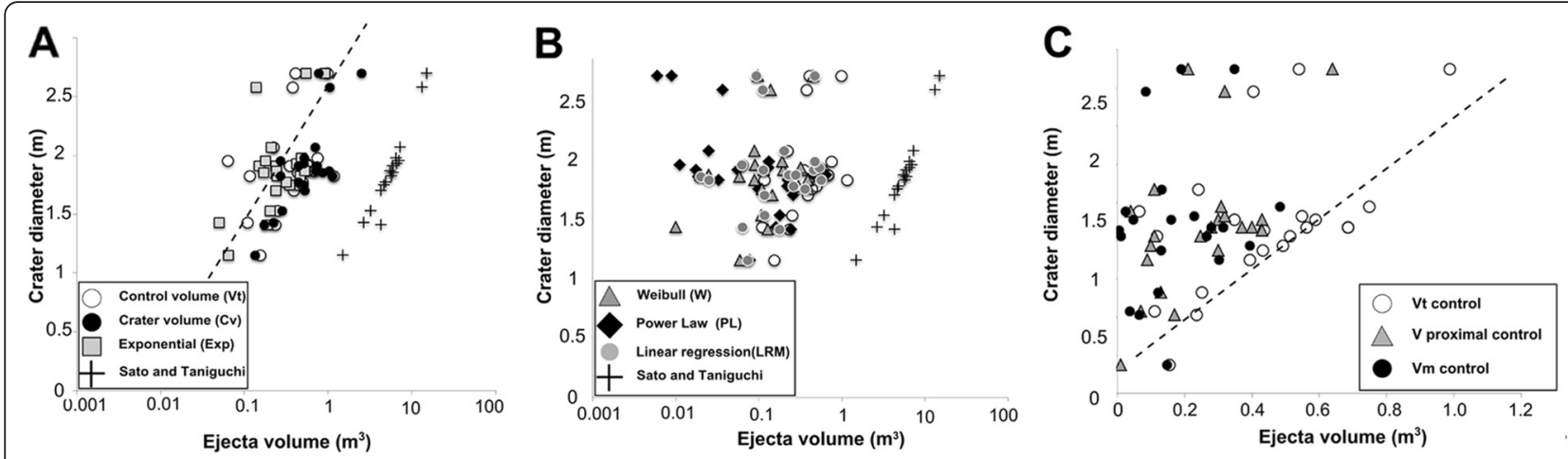

Fig. 3 Modeled deposit volumes versus crater diameter similar to Sato and Taniguchi (1997). Apparent relationships between ejecta volume and crater volume are model dependent. a Crater diameter and ejecta volume for the control volume, Crater volume dependent model, and Exponential model all present a weak log linear trend similar to data from Sato and Taniguchi. b Weibull, Power Law and LRM models all present no apparent trend. c Breaking the experimental control volume into proximal and medial components shows a weaker trend than the total volume

trend would be further disrupted by lateral vent migration, collapse and erosion of the crater and the variable volume of introduced magma (juvenile contributions) as occur in natural settings. Field and experimental studies are revealing the construction (and destruction) history of craters is far more complicated than previous single-blast experiments, or even the small number multiple blast craters as studied here. Therefore, it is not anticipated that this relationship will hold up for most natural craters (Ort and Carrasco-Núñez 2009; Son et al. 2012; Jordan et al. 2013; Blaikie et al. 2014; Valentine et al. 2015b).

Why do all of these models produce poor volume estimates for these experimental results? The answer lies in the fact that the models were designed for an inherently different process. The experimental deposits are the result of discrete explosions that produce jets that collapse rapidly (Graettinger et al. 2014) and create narrow deposits dominated by proximal ejecta (Graettinger et al. 2015a). The traditional models, however, are designed for widespread deposits produced by sustained buoyant plumes. It is only reasonable for such different deposits to present distinct patterns of decay with distance. The challenge in characterizing the proximal deposits, however, is not just the dramatic difference in slope between proximal and medial deposits. All of the models used here produced greater deviation from the control volumes for deposits produced by explosions through an existing crater (Table 2). In addition, all thickness-based models produced an underestimation of the explosion series volume $(V s)$, while $C v$ overestimated Vs. This indicates that the poor fit to secondary explosion deposits is not limited to the characterization of individual beds as a function of scale, rather, the total volume is highly sensitive to the proximal deposit, which composes an increasing portion of the total volume (50-90 \%) as the number of explosions increases within a crater (Graettinger et al. 2015a). The poor fit of the proximal deposits by these methods is in part due to the morphology of the proximal deposits, but also in part to how they change with subsequent explosions. Because of variations in crater width and its control on jet dynamics (Taddeucci et al. 2013; Graettinger et al. 2014), the proximal ring can vary in height, width and slope after each explosion, instead of having a consistent thickening from additional accumulation of ejecta. The $C v$ model fails to capture the deposit volume for a multiple-blast system because it does not allow for changes in density within the host material and the ejecta deposits. While most studies will not target volume estimates of each individual bed, the experimental data set studied here indicates the sensitivity of the models to the data available for input, particularly that of the proximal zone. This zone of deposition is not only variable and poorly represented by thickness-only measurements, but represents a significant portion of the final deposit volume. Any approach to estimating the total deposit volume will require high precision measurement of the proximal deposits. In most cases, a high resolution DEM will be the most effective solution. Because distal and medial deposits are much thinner, they are less likely to be preserved (e.g. Valentine and Cortés 2013). However, these discrete explosion produce deposits that are predominantly located in the proximal region (between $50-90 \%$ of the total volume; Graettinger et al. 2015a) reducing the influence of erosion of medial and distal deposit components on the total deposit volume.

\section{Summary and conclusion}

This assessment of classic tephra volume estimate models for their ability to reconstruct the volume of well-constrained deposits from discrete explosion and 
explosion sequences reveals the sensitivity of the estimates to proximal deposits and poor model fits to deposits where the proximal volume exceeds $50 \%$ of the total volume. Volume estimates of experimental deposits revealed that the models investigated here did not constrain proximal contributions to deposit volumes well, and the fit worsened with an increasing number of subsequent explosions within a crater. The Exponential and LRM models showed reasonable characterization of the medial and distal ejecta volumes $(\mathrm{Vm})$, suggesting that with additional data points in the proximal region the models may result in reasonable volume estimates. The Power Law and Weibull models, however, produced highly varied estimates, but typically underestimated deposit volumes. The Crater volume dependent model $(C v)$ was found to reproduce primary explosion volumes well, but did not produce appropriate results for subsequent blasts or total deposit volumes.

While proximal deposits may represent only a small area of the total deposit distribution, the contribution by volume is typically $50 \%$ or greater of the total volume, a value that increases with additional explosions within the system. This distribution reflects unique hazards with distance from the explosive vent for these types of eruptions in addition to the influence on volume estimates. In field campaigns it can be difficult to acquire sufficient thickness measurements in this proximal region to fully characterize the decay for models such as Exponential or LRM. Consequently, the best approach for these deposits is likely a combination of a digital elevation model to characterize the proximal deposits and an estimate of the medial and distal tephra using the Exponential model. In the event of widely distributed data with insufficient data to produce reasonable isopach maps, the Linear Regression Model proposed by Burden et al. (2013) will also provide reasonable volume estimates for the medial and distal tephra.

Additionally, the relationship between final crater diameter and ejecta volume was evaluated and found to be dependent on idealized eruption scenarios where the explosion locus experienced no lateral migration, the explosion did not interact with significant previous topography, or the crater was not altered dramatically by collapse or erosion. For maar-diatremes and other phreatic explosions these simple cases are not likely to be the norm. Accurate characterization of these deposit volumes and relative distribution of tephra volumes is vital to hazard assessments and numerical models. This evaluation of classic tephra models highlights important differences in the distribution of ejecta volumes from discrete subsurface explosions such as phreatomagmatic and hydrothermal explosions beyond simple scaling. Hazard models for these explosion types should incorporate improved volume estimates to improve risk management associated with this eruption style.

\section{Additional file}

Additional file 1: Table S1. Volumes calculated for $V m$ and $V t$ using various classic tephra volume estimates. All volumes are in $\mathrm{m}^{3}$. Uncertainty is derived from the cube of the vertical resolution of the digital elevation model estimates of Vp. (DOCX $20 \mathrm{~kb})$

\section{Abbreviations}

Cv: crater volume dependent; Exp: exponential; IncT: expanded incremental; LRM: linear regression model; PL: power law; Vm: medial and distal volume; Vp: proximal volume; Vs: series volume; Vt: total volume; W: Weibull.

\section{Competing interests}

The author declares that she has no competing interests.

\section{Acknowledgements}

This work is part of a larger project with G.A. Valentine and I. Sonder, and they are gratefully acknowledged for their suggestions that improved this manuscript. The datasets used in this study were from experiments partly supported by the US National Science Foundation (EAR 1420455 to G.A. Valentine) and by the $3 \mathrm{E}$ fund at the University at Buffalo. Additional contributions to the experiments from J.D. White, P.S. Ross, J. Taddeucci, D. Bowman, J. Lees, A. Harris, and M. Bombrun are gratefully acknowledged. Valuable assistance was provided by E. Dohring, C.G. Hughes, J. Krippner, E. Macorps, S. Morealli, and D.S.C. Ruth for data collection and processing Two anonymous reviewers assisted provided valuable feedback.

Received: 23 April 2015 Accepted: 1 April 2016

Published online: 11 April 2016

\section{References}

Blaikie TN, Ailleres L, Betts PG, Cas RAF. A geophysical comparison of the diatremes of simple and complex maar volcanoes, Newer Volcanics Province, south-eastern Australia. J Volcanol Geotherm Res. 2014;276:64-81. doi:10.1016/j.jvolgeores.2014.03.001

Bonadonna C, Costa A. Estimating the volume of tephra deposits: A new simple strategy. Geology. 2012;40:415-8. doi:10.1130/G32769.1.

Bonadonna C, Houghton BF. Total grain-size distribution and volume of tephrafall deposits. Bull Volcanol. 2005;67:441-56. doi:10.1007/s00445-004-0386-2.

Bonadonna C, Ernst GJ, Sparks RSJ. Thickness variations and volume estimates of tephra fall deposits: the importance of particle Reynolds number. J Volcanol Geotherm Res. 1998;81:173-87.

Breard E, Lube G, Cronin S, Fitzgerald R, Kennedy B, Scheu B, Montanaaro C, White JDL, Tost M, Procter JN, Moebis A. Using the spatial distribution and lithology of ballistic blocks to interpret the eruption sequence and dynamics: August 6, 2012 Upper Te Marri eruption, New Zealand. J Volcanol Geotherm Res. 2014;286:373-86. doi:10.1016/j.jvolgeores.2014.03.006.

Burden RE, Chen L, Phillips LF. A statistical method for determining the voume of volcanic deposits. Bull Volcanol. 2013;75:707. doi:10.1007/s00445-013-0707-4.

Christenson BW, Werner CA, Reyes AG, Sherburn S, Scott BJ, Miller C, Rosenburg MJ, Hurst AW, Britten KA. Hazards from Hydrothermally Sealed Volcanic Conduits. EOS Trans AGU. 2007:88(5):53-5. doi:10.1029/2007EO050002.

Daggitt ML, Mather TA, Pyle DM, Page S. AshCalc-a new tool for the comparison of the exponential, power-law and Weibull models of tephra deposition. J Appl Volcanol. 2014;3:7. doi:10.1186/2191-5040-3-7.

Engwell SL, Sparks RSJ, Aspinall WP. Quantifying uncertainties in the measuremnts of tephra fall thickness. J Appl Volcanol. 2013;2:1-12. doi:10.1186/2191-5040-2-5.

Fierstein J, Nathenson M. Another look at the calculation of fallout tephra volumes. Bull Volcanol. 1992:54:156-67.

Goto A, Taniguchi H, Yoshida M, Ohba T, Oshima H. Effects of explosion energy and depth to the formation of blast wave and crater: Field explosion experiment for the understanding of volcanic explosion. Geophys Res Lett. 2001;28:4287-90

Gould K, Tempo K. High-explosive Field Tests: Explosion phenomena and environmental impacts. In: Defense nuclear agency Santa Barbara, California 1981.

Graettinger AH, Valentine GA, Sonder I, Ross P-S, White JDL, Taddeucci J. Maardiatreme geometry and deposits: subsurface blast experiments with variable explosion depth. Geochem Geophys Geosyst. 2014. doi:10.1002/2013GC005198. 
Graettinger AH, Valentine GA, Sonder I, Ross P-S, White JDL. Facies distribution of ejecta in analog tephra rings from experiments with single and multiple subsurface explosions. Bull Volcanol. 2015a; doi:10.1007/s00445-015-0951-x.

Graettinger $\mathrm{AH}$, Valentine GA, Sonder I. Circum-crater variability of deposits from discrete, laterally and vertically migrating volcanic explosions: experimental evidence and field implications: J Volcanol Geotherm Res. 2015b;308:61-9. doi:10.1016/j.jvolgeores.2015.10.019.

Guilbaud M-N, Siebe C, Layer P, Salinas S. Reconstruction of the volcanic history of the Tacambaro-Puruaran area (Michoacan, Mexico) reveals high frequency of Holocene monogenetic eruptions. Bull Volcanol. 2012;74:1187-211. doi:10.1007/s00445-012-0594-0.

Houghton BF, Swanson DA, Rausch J, Carey RJ, Fagents SA, Orr TR. Pushing the Volcanic Explosivity Index to its limit and beyond: Constraints from exceptionally weak explosive eruptions at Kilauea in 2008. Geology. 2013;41:627-30. doi:10.1130/G34146.1.

Jordan SC, Cas RAF, Hayman PC. The origin of a large (>3 km) maar volcano by coalescence of multiple shallow craters: Lake Purrumbete maar, southeastern Australia. J Volcanol Geotherm Res. 2013;254:5-22. doi:10.1016/j.jvolgeores.2012.12.019.

Kereszturi G, Nemeth K, Cronin SJ, Agustin-Flores J, Smith IEM, Lindsay JM. A model for calculating eruptive volumes for monogenetic volcanoes- Implication for the Quaternary Auckland Volcanic Field, New Zealand. Journal of Volcanology and Geotherm Res. 2013;16-33. doi:10.1016/j.jvolgeores.2013.09.003.

Kilgour G, Manville V, Della Pasqua F, Graettinger A, Hodgson KA, Jolly GE. The 25 September 2007 eruption of Moutn Ruapehu, New Zealand: Directed Ballistics, sursteyan jets, and ice-slurry lahars. J Volcanol Geotherm Res. 2010;191:1-14. doi:10.1016/j.jvolgeores.2009.10.015.

Klawonn M, Houghton BF, Swanson D, Fagents SA, Wessel P, Wolfe C. From field data to volumes: constraining uncertainties in pyroclastic eruption parameters. Bull Volcanol. 2014a;76:869. doi:10.1007/s00445-014-0839-1.

Klawonn M, Houghton BF, Swanson DA, Fagents SA, Wessel P, Wolfe C. Constraining explosive volcanism: subjective choices during estimates of eruption magnitude. Bull Volcanol. 2014b;76:793. doi:10.1007/s00445-013-0793-3.

Lee CKB, Mazzola TA. Ejecta scaling laws for craters in dry alluvial sites. J Geophys Res. 1989;94:17595-605.

Moore JG, Nakamura K, Alcaraz A. The 1965 eruption of Taal Volcano. Science. 1966;151:955-60.

Ort MH, Carrasco-Núñez G. Lateral vent migration during phreatomagmatic and magmatic eruptions at Tecuitlapa Maar, east-central Mexico. J Volcanol Geotherm Res. 2009;181:67-77. doi:10.1016/j.jvolgeores.2009.01.003.

Pyle DM. Assessment of the minimum volume of tephra fall deposits. J Volcanol Geotherm Res. 1995;69:379-82.

R Core Team. R: A language and environment for statistical computing. R Foundation for Statistical Computing, Vienna, Austria. 2012 ISBN 3-900051-07-0, URL http://www.R-project.org/.

Rose W, Self S, Murrow PJ, Bonadonna C, Durant AJ, Ernst GJ. Nature and significance of small volume fall deposits at composite volcanoes: Insights from October 14, 1974 Fuego eruption, Guatemala. Bull Volcanol. 2008;70:1043-67. doi:10.1007/s00445-007-0187-5.

Sato $H$, Taniguchi $H$. Relationships between crater size and ejecta volume of recent magmatic and phreato-magmatic eruptions: Implications for energy partioning. Geophys Res Lett. 1997;24:205-8.

Son M, Kim JS, Jung S, Ki JS, Kim M-C, Sohn YK. Tectonically controlled vent migration during maar-diatreme formation: An example from a Miocene half-graben basin in SE Korea. J Volcanol Geotherm Res. 2012;223-224:29-46. doi:10.1016/j.jvolgeores.2012.02.002.

Sonder I, Graettinger AH, Valentine GA. Scaling multiblast craters: general approach and application to volcanic craters. J Geophys Res. 2015. doi:10.1002/2015JB012018.

Taddeucci J, Valentine GA, Sonder I, White JDL, Ross P-S, Scarlato P. The effect of pre-existing crater on the initial development of explosive volcanic eruptions: An experimental investigation. Geophys Res Lett. 2013;40:507-10. doi:10.1002/grl.50176.

Valentine GA, Cortés JA. Time and space variations in magmatic and phreatomagmatic eruptive processes at Easy Chair (Lunar Crater Volcanic Field, Nevada, USA. Bull Volcanol. 2013;75:752-65. doi:10.1007/s00445-013-0752-z.

Valentine GA, Graettinger AH, Macorps E, Ross P-S, White JDL, Dohring E, Sonder I. Experiments with vertically and laterally migrating subsurface explosions with applications to the geology of phreatomagmatic and hydrothermal explosion craters and diatremes. Bull Volcanol. 2015a;77:15. doi:10.1007/s00445-015-0901-7.

Valentine GA, Sottili G, Palladino DM, Taddeucci J. Tephra ring interpretation in light of evolving maar-diatreme concepts: Stracciacappa maar (central Italy): J Volcanol Geotherm Res. 2015b;308:19-29. doi:10.1016/j.jvolgeores.2015.10.010.

White JDL, Ross PS. Maar-diatreme volcanoes: A review. J Volcanol Geotherm Res. 2011;201:1-29. doi:10.1016/j.jvolgeores.2011.01.010.

\section{Submit your manuscript to a SpringerOpen ${ }^{\circ}$ journal and benefit from:}

- Convenient online submission

- Rigorous peer review

- Immediate publication on acceptance

- Open access: articles freely available online

- High visibility within the field

- Retaining the copyright to your article

Submit your next manuscript at springeropen.com 